\title{
How do socio-demographics and built environment affect individ- ual accessibility based on activity space? Evidence from Greater Cleveland, Ohio
}

\author{
$\mathrm{Na}$ Chen \\ The Ohio State University \\ chen.2572@buckeyemail.osu.edu
}

\author{
Gulsah Akar \\ The Ohio State University \\ akar.3@osu.edu
}

\begin{abstract}
Since the early 2000s, accessibility-based planning has been increasingly used to mitigate urban problems (e.g., traffic congestion and spatial mismatch) from a sustainable perspective. In particular, the concept of accessibility has been applied to investigate transport exclusion in many studies. However, few of them shed light on the effects of socio-demographics (e.g., income and gender) and the built environment (e.g., density) on accessibility at the individual level as a measure of transport exclusion. This study measures individual accessibility as the opportunities available per square mile within individual daily activity space for evaluating transport exclusion status based on the Capability Approach. Using data from the 2012 Northeast Ohio Regional Travel Survey and two opportunity sets (land uses and jobs), we calculate individual accessibility and compare them across three income groups. The comparisons report that low-income people are not disadvantaged in our study region. Path models are estimated to examine the relationships between socio-demographics, built environment, trip characteristics, and individual accessibility. We apply K-means cluster analysis to construct seven neighborhood types for the built environment. The results indicate that the effect of income on accessibility varies by opportunity types and living in urbanized neighborhoods increases people's accessibility after controlling for other characteristics.
\end{abstract}

\section{Article history:}

Received: December 2, 2016

Received in revised form: July

22, 2106

Accepted: August 9, 2016

Available online: September 23,

2016

\section{Introduction}

In the past two decades, accessibility-based planning has been popularly applied to contribute to the integration of transportation and land-use planning for improving urban sustainability (Bertolini, le Clercq, and Kapoen 2005). The concept of accessibility is a popular measurement for transport sustainability, in particular for the social dimension. It is generally recognized that among the three dimensions of sustainable transportation (efficiency, environment, and social equity), the social dimension has not attracted as much attention as the other two (Gilbert et al. 2002; Litman and Brenman 2012). This is in part because there are several types of social equity to consider, numerous impacts and ways of measuring those impacts, and various ways that people can be grouped for equity analysis (Litman

Copyright $2016 \mathrm{Na}$ Chen \& Gulsah Akar

http://dx.doi.org/10.5198/jtlu.2016.861

ISSN: 1938-7849 | Licensed under the Creative Commons Attribution - Noncommercial License 3.0

The Journal of Transport and Land Use is the official journal of the World Society for Transport and Land Use (WSTLUR) and is published and sponsored by the University of Minnesota Center for Transportation Studies. 
2002). Based on the Capability Approach developed by Sen (1980), which states that unfair outcomes are in fact caused from lack of accessibility to various resources, our study focus is on the research questions of whether certain social groups lack accessibility to different opportunities and how both sociodemographics and the built environment affect individual accessibility for transport exclusion analysis.

Accessibility was introduced as an explicit sustainable objective in the United Kingdom in 1998 (Atkins 2012; Geurs, Krizek, and Reggiani 2012; Halden 2014), defined as the ease of people to reach activities using one or more modes under certain constraints (Geurs and van Wee 2004; Shen 1998). Although this concept has been studied for transport exclusion in many studies (Kenyon, Lyons, and Rafferty 2002; Casas 2007; Bocarejo and Oviedo 2012), only a few examine individual-level accessibility, and most emphasize descriptive comparison of accessibility values by socio-demographic groups, without further investigating the explanatory factors on the level of accessibility (Kwan 1999; Páez et al. 2010).

Our research adds to the studies on the social dimension of sustainable transportation using data from the 2012 Northeast Ohio Regional Travel Survey (NORTS). First, we operationalize transportrelated social exclusion via an individual's activity space, since an individual-level analysis provides more information than the traditional zonal level. Second, the number of opportunities per square mile within an individual's activity space is determined through cumulative opportunity sets formed by land uses and jobs. The resulting activity space-based accessibility measures people's potential capability to reach services and activities based on their observed travel patterns. Third, we examine differences in accessibility across income groups. Finally, we examine the impact of the built environment at the residential locations and socio-demographics on individual accessibility while controlling for trip characteristic.

\section{$2 \quad$ Study background}

\subsection{Transport-related social exclusion}

Amartya Sen and a number of scholars have significantly contributed to the development of the Capability Approach (CA) since the 1980s (Sen 1980). This approach focuses on evaluating individual capability and opportunities to achieve "functionings," which are states of human beings and activities that a person can undertake (Sen 1980). This approach sheds light on equality of opportunity in terms of capability and functionings instead of equality of actual state and utility aggregation. It rejects the unfair distribution of income and other material resources as the only factor for social injustice and argues that the capability of the person should be the evaluation framework. Even though the CA provides a theoretical framework in social science for studying well-being, inequality, and public policies, its application is not yet common in transportation (Robeyns 2006; Beyazit 2011). Rashid, Yigitcanlar, and Bunker (2010) uses the CA to identify urban transportation disadvantage scenarios and also the factors that explain these scenarios. Smith, Hirsch, and Davis (2012) develops a minimum income standard (MIS) rural methodology under Sen's CA framework to identify transport disadvantage in rural England. The concept of "capability" in the CA framework represents a person's ability or opportunities to achieve a certain status (Clark 2005). Smith, Hirsch, and Davis (2012) claims that a broad set of capabilities (e.g., material resources, personal and environmental characteristics) determines people's "functionings," while this study understands transport-related equity as travelers' capabilities to use transport resources to participate in activities under personal and environmental constraints. This is termed "transport exclusion.”

Since the 2003 Social Exclusion Unit (SEU) study (2003) was conducted in the United Kingdom, there have been a number of studies exploring transport exclusion (Casas, Horner, and Weber 2009; Lucas et al. 2007; Handy 2002; Rashid, Yigitcanlar, and Bunker 2010; Pritchard et al. 2014; Preston and 
Rajé 2007). Rashid, Yigitcanlar, and Bunker (2010) scrutinizes four approaches in measuring transport exclusion, ranging from poverty to equity, mobility, and accessibility approaches. Casas et al. (2009) compares three measures for identifying transport exclusion: Deprivation index, cumulative accessibility, and space-time prisms. Lucas et al. (2007) presents five core indicators to assess the social sustainability of transport, including poverty, accessibility, safety, quality of life, and housing for different social changes related to transport. From transportation planners' and geographers' viewpoints, the most often used measures for transport exclusion analysis are based on mobility, accessibility, and activity space (Handy 2002; Schönfelder and Axhausen 2003; Casas 2007).

As to mobility, Handy (2002) suggests that it focuses on the sufficiency of means to travel, rather than the provision of opportunities and the connections between them. Most transport research specifies mobility as level-of-service, miles traveled and travel time (Litman 2002). This measure evaluates transportation based on vehicle travel, which favors motorized modes and ignores the connection between transportation networks and the land-use system (Litman 2002). This emphasis reinforces transport exclusion.

Some studies use activity space as a transport exclusion measure (Schönfelder and Axhausen 2003; Kamruzzaman and Hine 2012; Manaugh and El-Geneidy 2012). Activity space is defined as a geographic space that includes activity locations utilized by an individual or a household during a given time period (Horton and Reynolds 1971). Schönfelder and Axhausen (2003) calculates and compares three activity space measurements for different groups by age, gender, and income, but these variables are generally not significant when modeling their effects on activity spaces. This finding supports the notion that activity space itself is not a good indicator for transport exclusion (Kamruzzaman and Hine 2012; Sherman et al. 2005). For instance, a person with a smaller activity space may still be able to reach most discretionary activities or services nearby since the residence might be in a mixed-use walkable environment. This provides a hint as to the connection between activity space and accessibility. The definition of accessibility implies that the "access level" usually occurs within a certain spatial range. Therefore, we can calculate accessibility based on activity space, as we now discuss.

\subsection{Accessibility}

Using accessibility to investigate transport exclusion is theoretically supported by the CA framework because accessibility represents people's capabilities to access services and opportunities. The CA perspective highlights that capability relies not only on socioeconomic conditions but also on material resources and environmental and other socio-demographic characteristics (Smith, Hirsch, and Davis 2012; Rashid, Yigitcanlar, and Bunker 2010). The investigations of transport exclusion are often conducted through comparing accessibility for different social groups (e.g., race, income and gender). Delmelle and Casas (2012) evaluates transport inequity in terms of accessibility experienced by different zones defined by income, quality of transport system, and location in relation to main work areas. Similarly, Bocarejo and Oviedo (2012) explores the distribution of bus rapid transit (BRT)-based accessibility patterns based on neighborhood socioeconomic strata and find that middle-income groups enjoy the greatest accessibility. In addition, gender, age, disability, and wage level are important perspectives for transport exclusion analysis using accessibility (Casas 2007; Páez et al. 2010; Kwan 1999; Casas, Horner, and Weber 2009; Fan, Guthrie, and Levinson 2012).

\subsubsection{Measures of accessibility}

Many transport and geography studies have explored different accessibility measures (Geurs and van Wee 2004; Neutens et al. 2010; Páez, Scott, and Morency 2012). Geurs and van Wee (2004) analyzes 
four types of accessibility measures: Infrastructure-, location-, person-, and utility-based. As the most widely used type, location-based measures estimate the access to different opportunities in one zone to all other zones considering the impedance of travel distance. These measures originate from Hansen (1959) who defines accessibility as "a measurement of the spatial distribution of activities about a point, adjusted for the ability and the desire of people or firms to overcome spatial separation." The gravity model and cumulative-opportunity approach are the two well-known location-based accessibility measures. Based on gravity accessibility, Shen (1998) and Kawabata and Shen (2006) improve the measurement of employment accessibility at the traffic analysis zone level by accounting for job competition among workers commuting by auto and transit.

However, the aggregation feature of zonal location-based measures is often criticized when discussing individual heterogeneity. In contrast, person-based measures consider more individual characteristics. For instance, space-time measures based on Hägerstrand's (1970) time-geographic framework are developed through delimiting the area within reach given an individual's space-time constraint using a space-time prism. This prism is determined by the locations of activities, the distances between relevant locations, and the amount of time available for travel and activity participation (Kim and Kwan 2003; Burns 1979). The application is, however, limited by the strict data requirement on the detailed individual activity-travel data and also limited by the computational intensity and complex operational algorithms. Casas (2007), Casas, Horner, and Weber (2009), and Páez et al. (2010) utilize travel survey data to calculate individual accessibility using the cumulative-opportunity approach based on the distances traveled.

The present study combines some features of location- and person-based measures, measuring the availability of opportunities reachable within a specified threshold at the individual level. Based on Hansen's gravity model (1959), many accessibility studies specify the threshold using travel time or distance to draw a buffer within which to count opportunities (Páez et al. 2010; Bocarejo and Oviedo 2012; Delmelle and Casas 2012). This specification is a function of land-use patterns and the performance of the transportation system (Shen 1998) but ignores travelers' characteristics. By contrast, we adopt an activity-space approach based on individual spatial behavior that reflects preferences for a particular place over other places equally distant (Sherman et al. 2005; Golledge 1997). It considers the traveler's characteristics, the spatial distribution of the locations this traveler has been to, and the travel routes and the areas traveled through (Schönfelder and Axhausen 2003), and therefore captures more individual and environmental heterogeneity than simply applying one threshold to all people.

\subsubsection{Empirical analysis of accessibility}

There are two main research streams in the empirical analysis of accessibility: Socio-demographic group comparison, and graphical comparison between the spatial distributions of accessibility values and social groups (Delmelle and Casas 2012; Páez et al. 2010; Casas, Horner, and Weber 2009; Kwan 1999). For instance, Kwan (1999) compares individual access to urban opportunities by gender using a 1995 twoday travel diary dataset in Franklin County, Ohio, and finds that women in the sample have less access to urban opportunities than men. Delmelle and Casas (2012) map BRT-based accessibility to three different activities (hospitals, recreation, and libraries) using graphical comparison. The results suggest uneven patterns of accessibility by BRT among different income-level neighborhoods. These studies compare accessibility without controlling for other variables, which may result in the accessibility gap between different socioeconomic groups.

Casas (2007) calculates accessibility as the total number of opportunities available for an individual within her or his activity space, which is the buffering area within the longest trip distance. The au- 
thor compares individual accessibility between disabled and nondisabled groups and finds that disabled people can access fewer opportunities. Surprisingly, however, being disabled is no longer significant after controlling for other individual socio-demographics, residential location, and trip distance. Fan, Guthrie, and Levinson (2012) analyzes the impact of a public transit investment, the Hiawatha light-rail (LRT) line in Minneapolis, on transit-based job accessibility at the census block level. They define accessibility as jobs (low-, medium-, and high-wage) reachable from each block centroid within a 30-minute transit time. The study finds that the distribution and connectivity of the transit system strongly influence job accessibility, especially for low-wage jobs.

In these studies, the impact of the built environment is not a research focus. Accessibility is often counted as a built environment feature. In this study, it is specified as a measure integrating land-use patterns, transportation system, and travelers' characteristics. Although many findings on the linkage between the built environment and travel behavior are mixed and inconsistent (Zhang et al. 2012; Ewing and Cervero 2010), some recent studies show that combining individual land-use variables to create distinct urban and rural typologies may result in interesting findings (Clifton et al. 2012; Harding et al. 2012; Akar, Chen, and Gordon 2016; Chen and Akar 2016). For example, both Harding et al. (2012) and Chen and Akar (2016) apply K-means cluster analysis to land-use variables and find that people living in urban clusters have smaller activity spaces. This is consistent with the Akar, Chen, and Gordon (2016) study of average trip distance, which is found to be shorter in urbanized neighborhoods.

In contrast, most accessibility studies focus on socioeconomic factors that may influence accessibility (Casas 2007; Fan, Guthrie, and Levinson 2012) and only a few examine the impact of the built environment. For example, Levine et al. (2012) bases itself on the argument that density can affect regional work accessibility using auto in two ways: Higher density can reduce average travel speed and then degrade accessibility if holding distances constant; and higher density can increase proximity by shortening the distance between origins and destinations, and then increase accessibility if holding travel speed constant. Therefore, the study decomposes the effect of density on accessibility into speed and proximity effects and demonstrates that density can enhance accessibility if the proximity effect dominates the speed effect. Wang and Chen (2015) reports significant effect of the built environment (e.g., distances, population density and land-use shares) on job accessibility by different transportation modes using spatial autoregressive models.

In this study, the built environment characteristics are measured by three sets of variables: (i) Neighborhood types (constructed by $K$-means cluster analysis); (ii) job-population balance; and (iii) transit stop density. The variables used for creating the neighborhood types include population, employment and intersection densities, median age of housing stock, and the percentage of single-family detached houses. These variables represent most dimensions of the built environment, such as density, diversity, destination accessibility, distance and design (Cervero and Kockelman 1997; Ewing and Cervero 2010; Manaugh, Miranda-Moreno, and El-Geneidy 2010; Zhang et al. 2012). For instance, job-population balance is used to represent the "diversity" dimension and street design is described by intersection density.

\section{$3 \quad$ Study region and data}

Greater Cleveland, Ohio, is our study region (Figure 1a). The increasing number of newly vacant properties and continued urban sprawl in this region have led to an overall loss in population. In particular, Cuyahoga County lost about 0.4 percent of its population from 2011 to 2012, the second largest decline in the country during this period (Exner 2015). The region has also experienced the biggest percentage decline in the country for job access in recent years (Lefkowitz 2015).

Our work uses the 2012 Northeast Ohio Regional Travel Survey (NORTS) provided by the Ohio 
Department of Transportation (ODOT) ${ }^{1}$. The final survey sample includes 4540 households, 10,066 persons, 7213 vehicles, 70,333 trips, and 85,813 activities. Table 1 presents the descriptive statistics of some variables from the survey by county. In the survey sample, most respondents are white. In Cuyahoga County, about 39 percent of people are nonwhite. The mean age across these five counties is similar. Overall, the sampled individuals have an average household income of around $\$ 54,484$, and most sampled households own at least one vehicle per driver. About 89 percent of trips were made by car and only 0.8 percent of respondents used public transit.

For the built environment and transportation system related variables, data were assembled from the Cleveland Regional Transit Authority, 2010 Census, and 2006-2010 Census Transportation Planning Products (CTPP) based on the five-year American Community Survey (ACS). There are two opportunity databases, one containing parcel-level land uses (commercial, office, and industrial uses) and the other listing block-level jobs (retail, office, and industrial). We collected parcel data from county auditor offices and job data from the 2010 Longitudinal Employer-Household Dynamics (LEHD) Origin-Destination Employment Statistics (LODES).

Table 1: Descriptive statistics of 2012 Northeast Ohio Regional Travel Survey*

\begin{tabular}{|c|c|c|c|c|c|c|c|}
\hline & & Cuyahoga & Geauga & Lake & Lorain & Medina & Total \\
\hline \multicolumn{8}{|c|}{ Sample Percentage } \\
\hline \multirow[t]{2}{*}{ License } & Yes & $80.3 \%$ & $95.0 \%$ & $93.5 \%$ & $90.8 \%$ & $94.6 \%$ & $84.7 \%$ \\
\hline & No & $19.7 \%$ & $5.0 \%$ & $6.5 \%$ & $9.2 \%$ & $5.4 \%$ & $15.3 \%$ \\
\hline \multirow[t]{2}{*}{ Gender } & Male & $46.7 \%$ & $46.9 \%$ & $44.7 \%$ & $47.0 \%$ & $48.0 \%$ & $46.7 \%$ \\
\hline & Female & $53.3 \%$ & $53.1 \%$ & $55.3 \%$ & $53.0 \%$ & $52.0 \%$ & $53.4 \%$ \\
\hline \multirow[t]{2}{*}{ Race } & White & $61.6 \%$ & $94.8 \%$ & $95.9 \%$ & $88.3 \%$ & $94.6 \%$ & $72.4 \%$ \\
\hline & Nonwhite & $38.5 \%$ & $5.2 \%$ & $4.1 \%$ & $11.8 \%$ & $5.4 \%$ & $27.6 \%$ \\
\hline \multirow{2}{*}{ Education } & At least bachelor's degree & $30.0 \%$ & $41.4 \%$ & $30.2 \%$ & $30.8 \%$ & $35.3 \%$ & $31.0 \%$ \\
\hline & Below bachelor's degree & $70.0 \%$ & $58.6 \%$ & $69.8 \%$ & $69.2 \%$ & $64.7 \%$ & $69.0 \%$ \\
\hline \multirow[t]{2}{*}{ Employee } & Yes & $50.2 \%$ & $57.6 \%$ & $53.6 \%$ & $53.4 \%$ & $58.8 \%$ & $51.9 \%$ \\
\hline & No & $49.8 \%$ & $42.4 \%$ & $46.4 \%$ & $46.6 \%$ & $41.2 \%$ & $48.1 \%$ \\
\hline \multirow[t]{2}{*}{ Household head } & Yes & $46.2 \%$ & $42.0 \%$ & $45.1 \%$ & $43.1 \%$ & $42.7 \%$ & $45.2 \%$ \\
\hline & No & $53.8 \%$ & $58.0 \%$ & $54.9 \%$ & $56.9 \%$ & $57.4 \%$ & $54.8 \%$ \\
\hline \multirow[t]{4}{*}{ Lifecycle } & Household with children & $21.4 \%$ & $22.7 \%$ & $22.0 \%$ & $24.0 \%$ & $21.8 \%$ & $21.9 \%$ \\
\hline & Household with retiree & $17.1 \%$ & $17.6 \%$ & $23.5 \%$ & $17.8 \%$ & $12.7 \%$ & $17.5 \%$ \\
\hline & Adult student household & $1.6 \%$ & $1.1 \%$ & $0.6 \%$ & $0.7 \%$ & $0.3 \%$ & $1.3 \%$ \\
\hline & Adult household & $60.0 \%$ & $58.5 \%$ & $53.9 \%$ & $57.5 \%$ & $65.2 \%$ & $59.3 \%$ \\
\hline \multirow[t]{4}{*}{ Mode use } & Auto & $86.0 \%$ & $94.0 \%$ & $92.5 \%$ & $93.2 \%$ & $93.8 \%$ & $88.5 \%$ \\
\hline & Walk and bike & $12.5 \%$ & $5.0 \%$ & $6.6 \%$ & $6.2 \%$ & $5.3 \%$ & $10.3 \%$ \\
\hline & Public transit & $1.0 \%$ & $0.0 \%$ & $0.2 \%$ & $0.1 \%$ & $0.2 \%$ & $0.7 \%$ \\
\hline & Other & $0.5 \%$ & $1.0 \%$ & $0.7 \%$ & $0.5 \%$ & $0.7 \%$ & $0.5 \%$ \\
\hline \multicolumn{8}{|l|}{ Sample Mean } \\
\hline \multicolumn{2}{|l|}{ Age } & 45.1 & 48.7 & 47.6 & 46.5 & 46.3 & 45.8 \\
\hline \multicolumn{2}{|l|}{$\begin{array}{l}\text { Household } \\
\text { income (\$) }\end{array}$} & 50153 & 74205 & 58339 & 58942 & 70886 & 54484 \\
\hline Vehicles per & & 1.0 & 1.2 & 1.1 & 1.1 & 1.1 & 1.0 \\
\hline \multicolumn{2}{|l|}{ Household size } & 2.2 & 2.4 & 2.2 & 2.3 & 2.3 & 2.2 \\
\hline
\end{tabular}

*These statistics are based on the sample. They do not represent the weighted values. 


\section{$4 \quad$ Accessibility calculation}

The literature on accessibility calculation indicates that combining place- and person-based measures provides a straightforward approach to calculate individual accessibility. As a place-based measure, the cumulative-opportunity approach is commonly applied to count the number of opportunities available within a certain space. The specification of "space" is the key to calculate accessibility. Traditionally, the cumulative approach is based on a uniform distance from a fixed point and it cannot capture individual characteristics (Casas 2007; Páez et al. 2010). Our research identifies individual accessibility as opportunities per square mile available for an individual within his or her daily activity space. At this stage, we do not consider the distance decay of opportunities and treat all opportunities within the same activity space equal.

For reasons of confidentiality, the geographical coordinates of the locations visited by sampled individuals are unavailable: Only their traffic analysis zones (TAZs) are known. Thus, this study uses a gridcell approach, which is developed in our previous work (Chen and Akar 2016) to calculate individual activity space. The steps of this approach are briefly summarized here. First, if one individual has at least one long trip (defined as a single trip distance greater than 50 miles) (Collia, Sharp, and Giesbrecht 2003) or has only one activity for each survey day, he or she is excluded from the analysis. The travel days reported by the sampled persons are not exactly the same, so only the first completed travel day is used. Then, a spatial polygon for each individual is constructed using the Convex Hull Minimum Boundary Geometry (CVH) in ArcGIS to contain all activity locations (TAZ centroids of these locations). This $\mathrm{CVH}$ polygon represents the convex hull of a set of points that is the smallest convex set that contains the points (Barber, Dobkin, and Huhdanpaa 1996). This polygon is not directly used as the activity space due to the limitation from the restricted coordinates of all locations. If one person conducts all of his or her activities in one TAZ, then we will get a point by using the CVH tool in ArcGIS. Therefore, we use the $\mathrm{CVH}$ polygon to identify which spatial units it intersects and then these units are aggregated as the activity space for each person. The TAZ was initially determined as the spatial unit. However, the varying size of the TAZs in different areas may introduce spatial bias. To minimize such bias, the whole study region is divided into a polygon shapefile with squared equally sized gridcells $(0.25$ miles $\mathrm{x} 0.25$ miles). For each person, the CVH polygon is spatially joined with these gridcells, and then we can identify which cells intersect with this $\mathrm{CVH}$ polygon. Then all the intersected cells' areas for this polygon are aggregated as the daily activity space for each individual. Figure $1 \mathrm{~b}$ shows an example for identifying one person's activity space on the first completed travel survey day with seven activities in seven different TAZs.

We then use this activity space to calculate individual accessibility to two groups of opportunities. The first is based on three categories (commercial, office, and industrial) of land use. The average area of these parcels within the study region is 0.003183 square miles, so we treat them as points at the parcel centroids. Accessibility to each land-use type is calculated as the number of parcel centroids falling into the identified activity space divided by the area size of that activity space. This division is used to control for the size of activity spaces. The second is based on three categories (retail, office, and industrial) of block-level jobs. Accessibility to each job type is calculated as the number of jobs (of a given category) falling into the activity space divided by the area size of that activity space. Our study adopts these two opportunity sets to represent different needs for the quality of life. For instance, the distribution of these three categories of land uses indicates the availability of basic services and activity locations that support people's daily lives, such as grocery shopping, dining, and entertainment. Differently, the distribution of jobs is related to the employment market and people's potential economic opportunity. Figures 1c and $1 \mathrm{~d}$ illustrate these two cases of accessibility. We also aggregate the three subcategories for each case. 


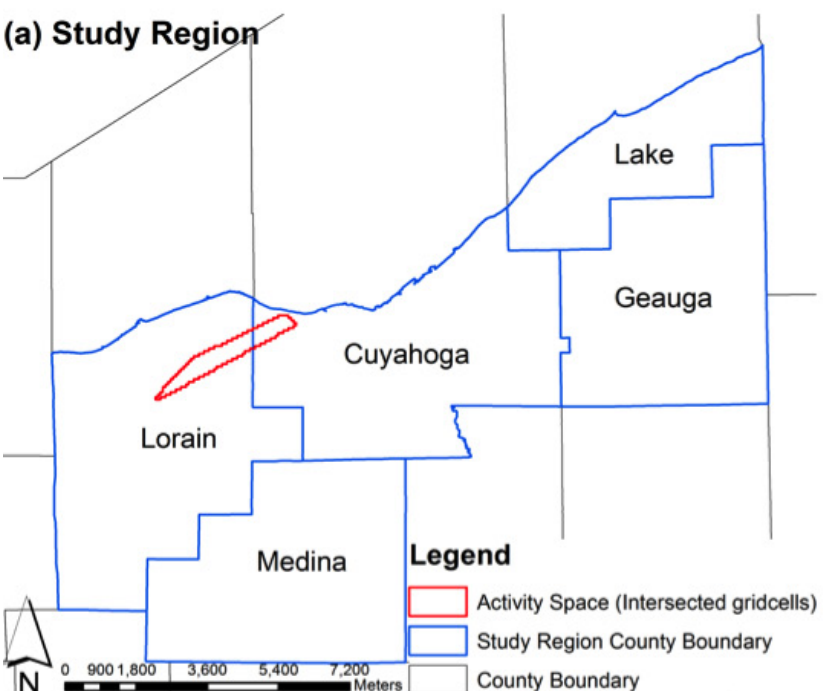

(b) Activity Space Calculation

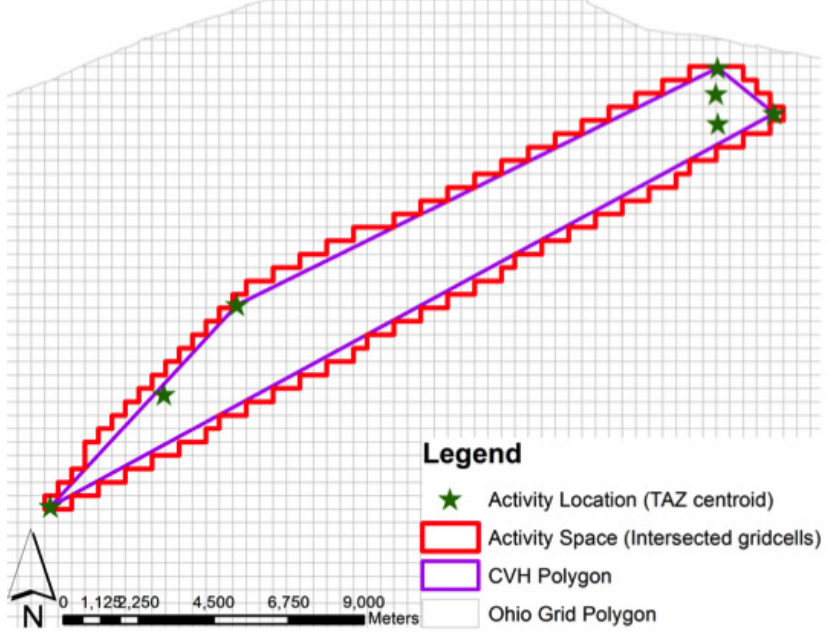

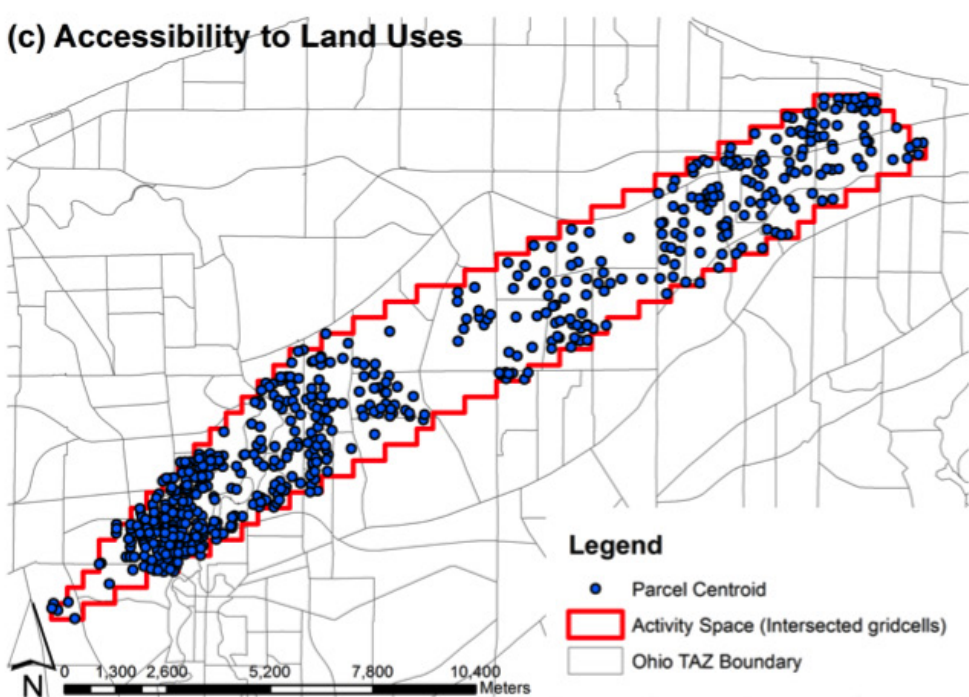

(d) Accessibility to Jobs

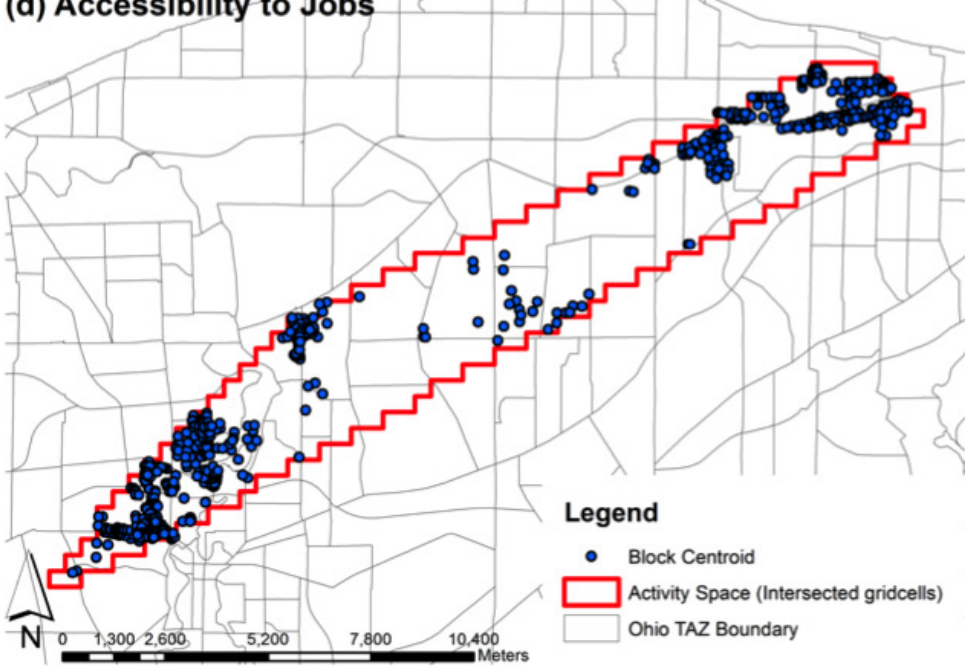

Figure 1: Example of activity space and accessibility calculation

\section{$5 \quad$ Cluster analysis}

Cluster analysis is a data mining tool to form "clusters" of highly similar entities, which for us are the TAZs of the Greater Cleveland region (Pang-Ning, Steinbach, and Kumar 2006; Aldenderfer and Blashfield 1984). The entities within the same cluster are assumed to be similar to each other and different from the ones in other clusters. The techniques for constructing clusters are diverse due to different types of clusterings (e.g., hierarchical versus partitional and exclusive versus overlapping versus fuzzy) and clusters (e.g., well-separated, prototype-based, graph-based, density-based, and shared-property) (PangNing, Steinbach, and Kumar 2006). One common algorithm for partitional clustering is the $K$-means method that requires the researcher to specify the number of clusters $(K)$ a priori. Then the centroid of each cluster is defined as the cluster mean. Each of those points representing the entities in the dataset is assigned to the nearest centroid. The next step is to update the cluster mean (centroid) again using the entities assigned to the cluster (Pang-Ning, Steinbach, and Kumar 2006). Then all entities are reassigned 
to clusters based on the new cluster means. This process is repeated until no entity changes clusters.

The application of $K$-means cluster analysis to the built environment variables to construct neighborhood types has previously been used to decrease the ambiguity of their effects on travel behavior (Akar, Chen, and Gordon 2016; Harding et al. 2012; Chen and Akar 2016). The neighborhood types constructed for this study are the same as Chen and Akar (2016) by using the same datasets and five built-environment variables (densities of population, employment, and intersection, median age of housing stock, and percentage of single-family detached houses). The calculations of these variables can be referred to this previous work. Our whole study region (1551 TAZs) is classified into seven clusters after trying other K options. These seven clusters are ordered based on descending order of population density. As Table 2 presents, Cluster 1 has the highest population density and Cluster 7 has the lowest. Based on the descriptive statistics of these five built environment variables, seven types of neighborhoods are used to describe these clusters:

- Cluster 1: High-density and mixed-use central neighborhoods

- Cluster 2: Central business district (CBD)

- Cluster 3: Medium-density urban neighborhoods

- Cluster 4: New dense residential neighborhoods

- Cluster 5: High-employment urban neighborhoods

- Cluster 6: Low-density and mixed-use suburban neighborhoods

- Cluster 7: Low-density single-family neighborhoods

Figure 2 shows that neighborhoods classified as Cluster 1 are located in urban cores in Cleveland characterized by mixed and old housing stock. The features of high densities in employment and intersection and few single-family detached houses indicate the TAZs assigned to Cluster 2 form the CBD. TAZs belonging to Clusters 3 and 4 are distributed surrounding urban cores. The characteristics of Cluster 5 denote that these TAZs are the second commercial and industrial areas with high employment and dense street networks. The suburban neighborhoods (Clusters 6 and 7) cover most areas of our study region, with the features of low-density and new residential developments. We exclude Cluster 2 (i.e., the CBD) from other tables and model estimations because there is only one sampled household in this cluster. 


\section{Legend}

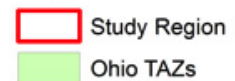

\section{Clusters}

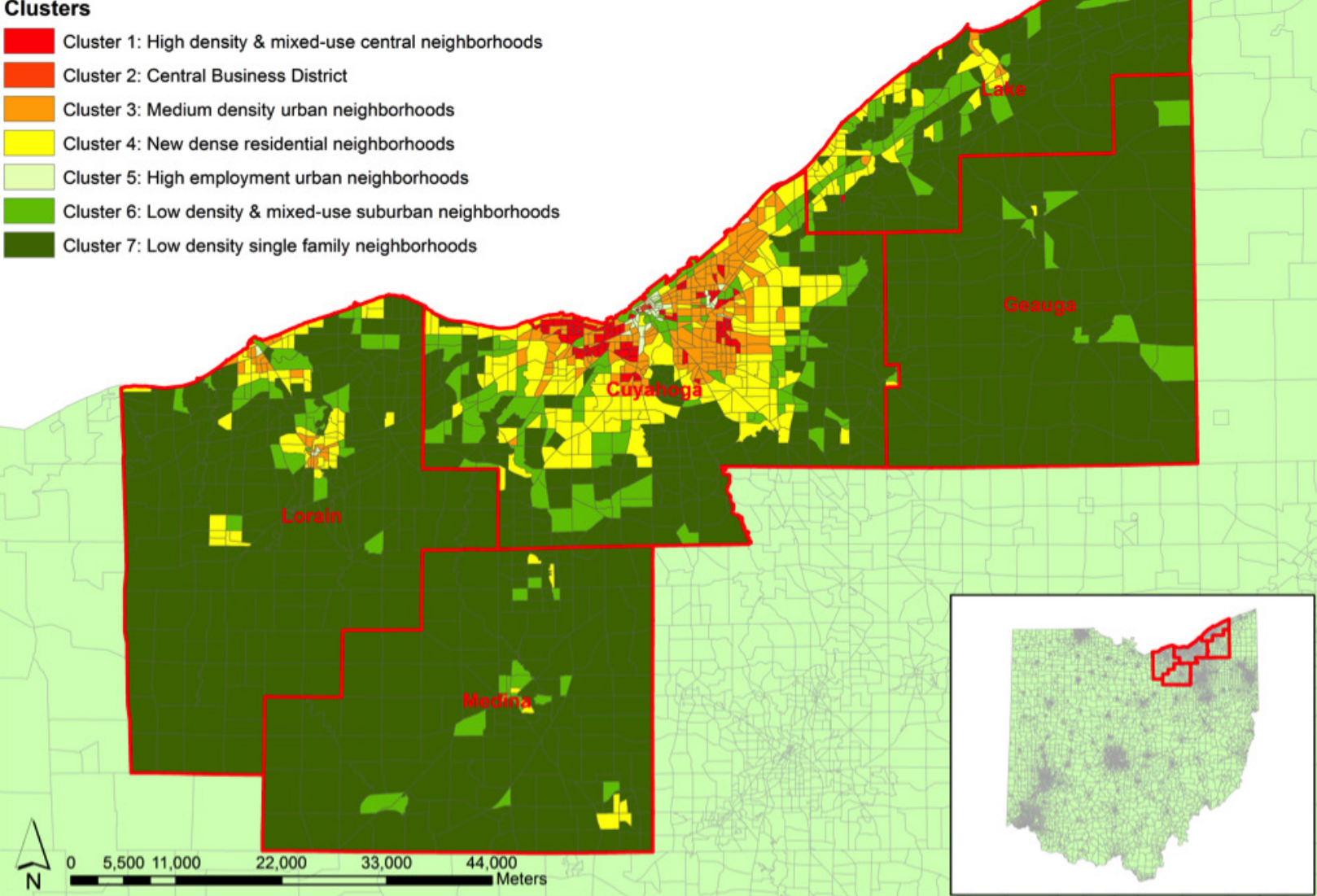

Figure 2: Cluster distribution in Greater Cleveland (TAZ)

Table 2: Descriptive statistics of built environment variables for clusters

\begin{tabular}{cccccccccc}
\hline & \multicolumn{1}{c}{ Clusters } \\
\hline Variables & & 1 & $2^{*}$ & 3 & 4 & 5 & 6 & 7 & Average \\
\hline Population Density & Mean & 12658.69 & 8102.12 & 5967.57 & 4092.02 & 3766.98 & 1719.91 & 861.36 & 3035.90 \\
(persons/square mile) & S. D. & 4970.39 & 13000.25 & 2055.91 & 1714.32 & 3308.54 & 1543.12 & 932.68 & 3672.99 \\
\hline Employment Density & Mean & 2638.78 & 237141.60 & 1692.68 & 1123.77 & 23077.80 & 2196.54 & 386.53 & 2787.35 \\
(persons/square mile) & S. D. & 6705.46 & 77364.41 & 2384.11 & 1437.55 & 26445.97 & 3359.56 & 905.17 & 17643.60 \\
\hline \multirow{2}{*}{ Intersection Density } & Mean & 222.39 & 416.50 & 206.24 & 131.23 & 421.01 & 96.32 & 43.02 & 110.80 \\
& S. D. & 109.69 & 268.94 & 76.76 & 44.12 & 154.20 & 67.63 & 39.45 & 107.09 \\
\hline \multirow{2}{*}{ Median Age of Structures } & Mean & 66.28 & 64.54 & 67.04 & 53.94 & 61.23 & 39.79 & 34.34 & 45.70 \\
& S. D. & 11.21 & 12.59 & 6.06 & 8.20 & 14.39 & 14.73 & 11.52 & 17.12 \\
\hline \multirow{2}{*}{ Percent Single Detached House } & Mean & 31.29 & 0.25 & 50.07 & 81.19 & 7.48 & 24.17 & 91.27 & 68.27 \\
& S. D. & 19.46 & 0.66 & 16.20 & 14.20 & 13.72 & 19.36 & 12.19 & 31.82 \\
\hline Number of TAZs & & 90 & 7 & 213 & 266 & 44 & 216 & 715 & 1551 \\
\hline
\end{tabular}

* Cluster 2 is kept as a cluster itself in this table because it represents the CBD but is excluded from the model estimations because only one sampled household resides in this cluster. 


\section{$6 \quad$ Methods}

\subsection{Accessibility comparison}

We will focus on accessibility comparison in terms of income. According to the 2010 US Census, the median household income in Greater Cleveland is $\$ 46,231$. Based on this value and relevant studies (Niemeier 1997; Páez et al. 2010), we categorize the sampled individuals into three groups:

- Low income: $\leq \$ 30,000$

- Medium income: $\$ 30,000-\$ 87,500$

- High income: $>\$ 87,500$

We compare the mean values of accessibility between every two of these income groups using the independent sample t-test.

\subsection{Path analysis}

In accessibility studies, trip distance is an important variable to calculate and affect accessibility. However, these studies do not consider the simultaneous interrelationships between accessibility, trip distance, and other exogenous variables. For instance, socio-demographics and the built environment influence not only accessibility but also travel behavior (Wang and Chen 2015; Akar, Chen, and Gordon 2016). Accessibility and travel behavior affect each other to some extent. Many travel behavior studies have reported that better accessibility decreases trip distances (Kockelman 1997; Krizek 2003), while Casas (2007) and Páez et al. (2010) present that one person's accessibility is affected by the distance traveled. These relationships indicate that some exogenous variables may affect accessibility and trip distance either directly or indirectly through either of these two endogenous variables. It is therefore not sufficient to only examine these relationships using traditional regression methods.

As a special case of structural equation modeling (SEM) without latent variables, path analysis provides a method of modeling mediation, indirect effects and other complex relationships among variables (Schumacker and Lomax 2004). We use path analysis to estimate the relationships among accessibility, trip distance, and three groups of exogenous variables. Based on literature review and some model experiments, our research hypotheses are illustrated in the path diagram (Figure 3). This study considers accessibility and average trip distance at the individual level as two endogenous variables. Since the effect of accessibility on average trip distance is not significant, this direction is dropped from the modeling framework: This makes average trip distance a mediating endogenous variable between accessibility and exogenous variables. The path coefficients are estimated using covariance analysis to make the variances and covariance matrix predicted by the model as similar as possible to the observed variance-covariance matrix (Golob 2003). This study uses the maximum likelihood method for the covariance analysis by assuming there is no excessive kurtosis. 


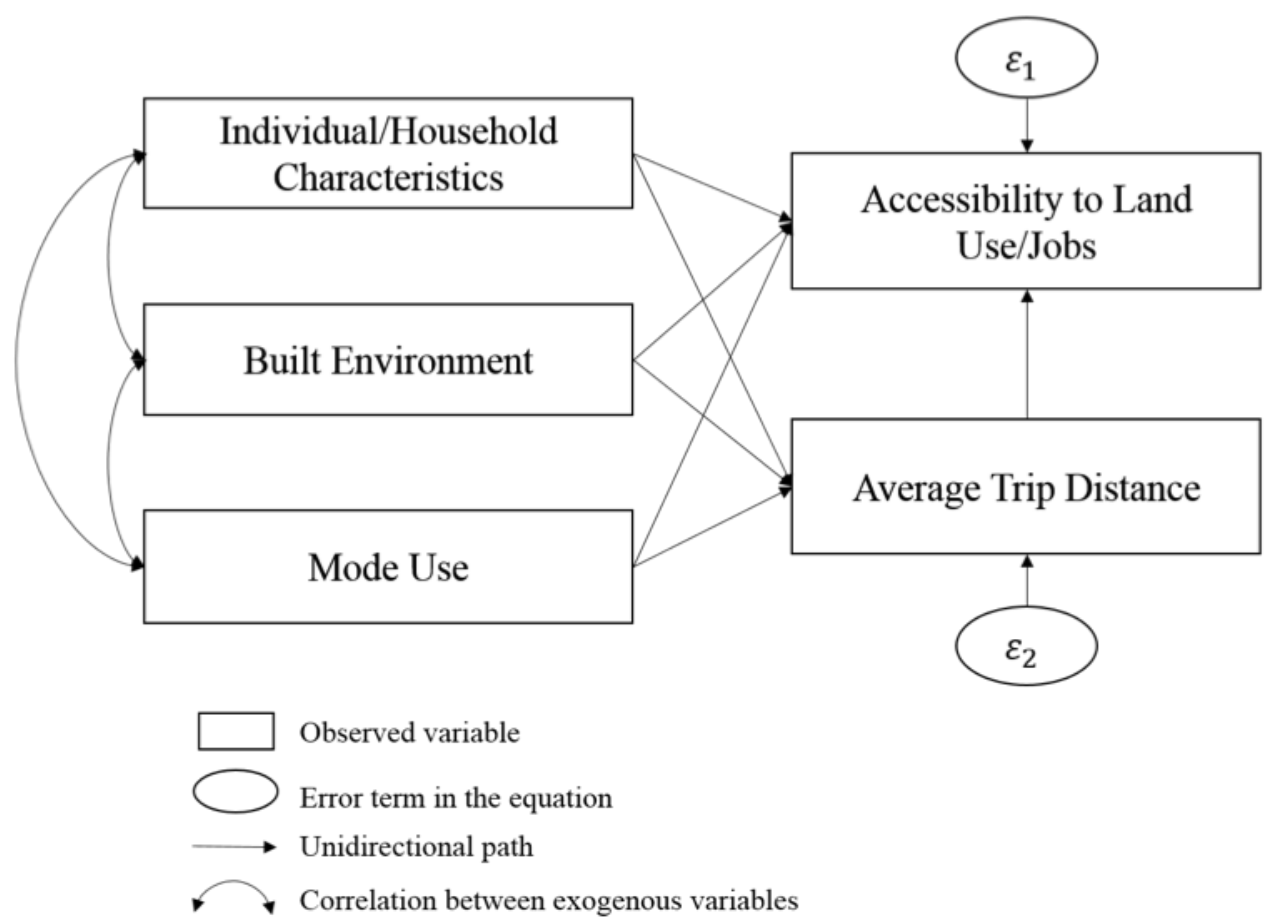

Figure 3: Path model diagram

\subsection{Endogenous and exogenous variables}

Table 3 summarizes the endogenous and exogenous variables with their definitions, means, and standard deviations based on the estimation sample. The number of observations is 5929 after excluding observations with missing data. We distinguish two modes of accessibility: To land use and to jobs using the categories previously defined. Average trip distance is obtained by dividing the total trip distance by the number of trips for each person during the first survey day. Individual and household characteristics include age, license status, gender, race, education level, household structure, employment status, household size, household income, and vehicle ownership. The built environment is characterized by three types of variables, including the seven new neighborhood types as previously discussed, the jobpopulation balance index based on Ewing et al. (2011), and transit proximity, which is measured as transit stop density within the TAZ for each residential location. The balance index ranges from 0 to 1 . The higher the value, the better balance in terms of jobs and population. Auto use is a dummy variable that takes the value of 1 if the person only uses auto for all the trips during the first survey day. County variables are controlled for regional effect. 
Table 3: Descriptive statistics of variables

\begin{tabular}{|c|c|c|c|c|}
\hline Variable & Description & Variable Type & Mean & S.D. \\
\hline Activity space & Activity space (square miles) per person within first completed travel day & Variable for calculating accessibility & 12.34 & 21.69 \\
\hline $\mathrm{A}^{\mathrm{LU}}$ & $\begin{array}{l}\text { Aggregated number of commercial, office, and industrial uses accessible per } \\
\text { square mile within activity space }\end{array}$ & Endogenous & 103.10 & 107.89 \\
\hline $\mathrm{A}^{\mathrm{COMU}}$ & Number of commercial use accessible per square mile within activity space & Endogenous & 68.47 & 69.51 \\
\hline $\mathrm{A}^{\mathrm{OFFU}}$ & Number of office use accessible per square mile within activity space & Endogenous & 5.11 & 9.97 \\
\hline $\mathrm{A}^{\mathrm{INDU}}$ & Number of industrial use accessible per square mile within activity space & Endogenous & 29.52 & 45.45 \\
\hline $\mathrm{A}^{\mathrm{JOB}}$ & $\begin{array}{l}\text { Aggregated number of retail, office, and industrial jobs accessible per square } \\
\text { mile within activity space }\end{array}$ & Endogenous & 2047.76 & 4125.23 \\
\hline $\mathrm{A}^{\mathrm{RJOB}}$ & Number of retail jobs accessible per square mile within activity space & Endogenous & 481.87 & 970.10 \\
\hline $\mathrm{A}^{\mathrm{OJOB}}$ & Number of office jobs accessible per square mile within activity space & Endogenous & 1224.73 & 3516.52 \\
\hline $\mathrm{A}^{\mathrm{IJOB}}$ & Number of industrial jobs accessible per square mile within activity space & Endogenous & 341.16 & 684.06 \\
\hline $\begin{array}{l}\text { Average trip } \\
\text { distance }\end{array}$ & Average trip distance (miles) per person within first completed travel day & Endogenous & 5.77 & 5.15 \\
\hline Auto use & $\begin{array}{l}\text { Dummy variable ( } 1 \text { if the individual only uses auto for his or her trips within } \\
\text { the first completed travel day; } 0 \text { otherwise) }\end{array}$ & Exogenous & 0.88 & 0.33 \\
\hline Age & Age of individual respondent & Exogenous & 51.54 & 17.51 \\
\hline License status & Dummy variable ( 1 if the individual has a valid driver license; 0 otherwise) & Exogenous & 0.92 & 0.28 \\
\hline Female & Dummy variable ( 1 if the individual is female; 0 otherwise) & Exogenous & 0.54 & 0.50 \\
\hline Race & Dummy variable ( 1 if the individual is non-white; 0 otherwise) & Exogenous & 0.23 & 0.42 \\
\hline Education & $\begin{array}{l}\text { Dummy variable ( } 1 \text { if the individual has bachelor's or higher degree; } 0 \text { other- } \\
\text { wise) }\end{array}$ & Exogenous & 0.39 & 0.49 \\
\hline Employee & Dummy variable ( 1 if the individual is employed; 0,otherwise) & Exogenous & 0.56 & 0.50 \\
\hline Income & $\begin{array}{l}\text { Dummy variables ( } 1 \text { if the individual is in a household with the corresponding } \\
\text { income level; } 0 \text { otherwise) }\end{array}$ & Exogenous & & \\
\hline Low income & Equal or less than $\$ 30,000$ & & 0.31 & 0.46 \\
\hline Med income & Greater than $\$ 30,000$ and equal or less than $\$ 87,500$ & & 0.53 & 0.50 \\
\hline High income & Greater than $\$ 87,500$ & & 0.16 & 0.37 \\
\hline Household head & Dummy variable ( 1 if the individual is the householder; 0 otherwise) & Exogenous & 0.54 & 0.50 \\
\hline Vehicles per driver & Number of vehicles per driver at the household level & Exogenous & 0.99 & 0.44 \\
\hline Household size & Number of members in a household & Exogenous & 2.71 & 1.37 \\
\hline Presence of retiree & Dummy variable ( 1 if there is a retiree or more in a household; 0 otherwise) & Exogenous & 0.12 & 0.33 \\
\hline $\begin{array}{l}\text { Presence of another } \\
\text { worker }\end{array}$ & $\begin{array}{l}\text { Dummy variable ( } 1 \text { if there is another worker in a household except for the } \\
\text { respondent; } 0 \text { otherwise) }\end{array}$ & Exogenous & 0.40 & 0.49 \\
\hline Transit stop density & Number of bus stop per square mile within the TAZ of the residential location & Exogenous & 22.18 & 29.52 \\
\hline JOBPOP & Index that measures the employment and population balance at the TAZ level & Exogenous & 0.46 & 0.28 \\
\hline Cluster indicators & $\begin{array}{l}\text { These variables are all dummy variables for the new neighborhood types ( } 1 \text { if th } \\
\text { otherwise) }\end{array}$ & e TAZ of the residential location is in & given clus & ter; 0 \\
\hline Cluster 1 & High-density and mixed-use central neighborhoods & Exogenous & 0.08 & 0.27 \\
\hline Cluster 3 & Medium-density urban neighborhoods & Exogenous & 0.20 & 0.40 \\
\hline Cluster 4 & New dense residential neighborhoods & Exogenous & 0.28 & 0.45 \\
\hline Cluster 5 & High-employment urban neighborhoods & Exogenous & 0.01 & 0.10 \\
\hline Cluster 6 & Low-density and mixed-use suburban neighborhoods & Exogenous & 0.10 & 0.31 \\
\hline Cluster 7 & Low-density single-family neighborhoods & Exogenous & 0.32 & 0.47 \\
\hline County indicators & Dummy variables for five counties in the study region ( 1 if the TAZ of the resid & lential location is in a given county; 0 & therwise) & \\
\hline Cuyahoga & & Exogenous & 0.64 & 0.48 \\
\hline Geauga & & Exogenous & 0.04 & 0.20 \\
\hline Lake & & Exogenous & 0.11 & 0.32 \\
\hline Lorain & & Exogenous & 0.14 & 0.35 \\
\hline Medina & & Exogenous & 0.06 & 0.24 \\
\hline \multicolumn{2}{|c|}{ Number of Observations } & & & 5929 \\
\hline
\end{tabular}




\section{$7 \quad$ Results and discussions}

\subsection{Accessibility comparison results}

We first compare accessibility to land uses and jobs respectively across three income groups in the sample. Table 4 shows that individuals in medium-income households have higher accessibility to aggregated land uses and to commercial and industrial parcels than high-income persons. Interestingly, the low-income people in the study region significantly access more parcels as compared to other two income groups. Job accessibility is an important equity focus as a proxy for economic capability. Similar to land uses, low-income people in the sample have significantly higher accessibility to all jobs except for retail category than the other two income groups. Most similar studies focus exclusively on examining total job accessibility at an aggregate level (Lubin and Deka 2012; Wang and Chen 2015). Our research contributes to existing studies by examining accessibility to three different categories of jobs at an individual level.

These findings suggest that based on our study region and data the low-income people, who are often socially disadvantaged, do not suffer from lower accessibility in terms of opportunities per square mile within their own activity spaces. However, here we consider only accessibility as a function of income, and it is interesting to know whether our conclusions change after controlling for other relevant variables.

Table 4: Accessibility comparisons (t-test values)

\begin{tabular}{|c|c|c|c|c|}
\hline & \multicolumn{4}{|c|}{ Income } \\
\hline & Low vs Medium & Low vs High & Medium vs High & Low vs All other \\
\hline \multicolumn{5}{|c|}{ Accessibility to land use } \\
\hline Total & $19.671^{* * *}$ & $16.932^{* * *}$ & $5.187^{* * *}$ & $22.861^{* * *}$ \\
\hline Commercial & $19.734^{* * *}$ & $17.682^{* * *}$ & $5.685^{* * *}$ & $23.115^{* * *}$ \\
\hline Office & $5.714^{* * *}$ & $3.972^{* * *}$ & 0.118 & $6.217^{* * *}$ \\
\hline Industrial & $14.848^{* * *}$ & $11.885^{* * *}$ & $3.688^{* * *}$ & $17.219^{* * *}$ \\
\hline \multicolumn{5}{|c|}{ Accessibility to jobs } \\
\hline Total & $5.556^{* * *}$ & $2.730^{* *}$ & -1.011 & $5.465^{* * *}$ \\
\hline Retail & $2.476^{*}$ & 1.458 & -0.101 & $2.740^{* *}$ \\
\hline Office & $5.359^{* * *}$ & $2.140^{*}$ & -1.558 & $5.020^{* * *}$ \\
\hline Industrial & $2.446^{*}$ & $4.524^{* * *}$ & 1.582 & $3.240^{* * *}$ \\
\hline
\end{tabular}

${ }^{*} \mathrm{p}<.05 ;{ }^{* *} \mathrm{p}<.01 ;{ }^{* * *} \mathrm{p}<.001$

\subsection{Path analysis results}

Our study uses AMOS software (IBM SPSS Amos, Version 22) (Blunch 2008) to estimate path models for each type of accessibility and average trip distance (eight path models), reporting both unstandardized and standardized direct, indirect, and total effects.

In the bottom part of Tables 5 and 6, we present several commonly used model-fit criteria. The chi-square test examines whether the observed and predicted covariance matrices are similar. Hence, an insignificant chi-square value indicates that the estimated model is regarded as acceptable since the observed covariance matrix is similar to the covariance matrix predicted by the estimated model. The Root Mean Square Error of Approximation (RMSEA) is a parsimony-adjusted index that measures the approximation error. The acceptable level for RMSEA is that the value is less than or equal to 0.05 (Schumacker and Lomax 2004). The Comparative Fit Index (CFI) measures the improvement in fit of 
our models compared with a least restrictive model. A CFI value that is close to 0.9 or 0.95 represents a good fit (Schumacker and Lomax 2004). The Akaike Information Criterion (AIC) compares models with differing numbers of parameters. A fitted model with a smaller AIC as compared to the saturated model (all variables correlated with all others) is preferred. The AICs reported in Tables 5 and 6 are smaller than the corresponding saturated models (AICs are not reported for saturated models in tables). This set of fit indices indicates that our eight models are estimated appropriately based on the hypothesized relationships.

We report standardized effects in Tables 5 and 6 for the eight path models. Each path model includes two endogenous variables: One type of accessibility and average trip distance. If an exogenous variable is not statistically significant at the 0.1 level, it is dropped. The categorical variables that are not significant are indicated using brackets. The modeling results are summarized as follows.

The direct effect of average trip distance on accessibility varies by different opportunities. As average trip distance increases, the individual accessibility to commercial parcels and retail jobs decreases, while the accessibility to industrial parcels and jobs increases. The effects of average trip distance on aggregated accessibility (both land uses and jobs) and accessibility to office opportunities are not significant. Since our accessibility is a density variable considering the size of each individual's activity space, longer average trip distance does not always guarantee high accessibility as Casas (2007) finds. Our opposite finding between accessibility to commercial and industrial opportunities is consistent with the trend of having more and larger industrial developments in urban edges near transportation assets such as freight rail, highways, and airports. Accessing more industrial developments needs farther travel. When people only use auto for all trips, their accessibility decreases, except for accessibility to industrial parcels and jobs that are only positively affected through the indirect effect from average trip distance. This supports the findings regarding the varying effects of average trip distance on different types of accessibility.

Usually, travelers at risk of social exclusion are the elderly, female, or people in households with low income (Schönfelder and Axhausen 2003; Litman 2002). In this study, the sampled individuals are categorized into five age groups and the base group includes the ones who are between the ages of 36 and 50. The results report that middle-aged individuals travel longer and have higher accessibility to commercial and industrial uses than adolescents (19 years or younger) and the elderly (65 years or older). Corresponding to the results on average trip distance and auto use, having a valid driver license decreases individual accessibility to commercial parcels and retail and office jobs, either directly or indirectly, while increasing accessibility to industrial opportunities indirectly. Being female significantly decreases a person's accessibility to industrial parcels and jobs and average trip distance. As compared to other races, non-white people can access more opportunities in terms of the three categories of land uses and office jobs per square mile within their activity spaces. As expected, individuals being employed or with a higher education level have higher accessibility to office opportunities. Under most circumstances, a good educational background or being employed can increase people's social inclusion through accessing more social activities. Household characteristics such as household size and presence of retiree are significantly and negatively associated with average trip distance, but most of them indicate insignificant direct effects on accessibility.

In accessibility comparisons, we find that low-income people in the sample do not suffer from lower accessibility in terms of opportunities per square mile within their own activity spaces. After controlling for other variables, the effects of income on accessibility are mixed. The results of direct effects suggest that an individual in a low-income household has higher accessibility to commercial and industrial parcels but accesses fewer office jobs per square mile within his or her activity space. It is widely known that most mono-centric urban areas in North America have experienced a continuing suburbanization of population and decentralization of employment from central city areas to suburban 
areas. Relatively poor people are the major residents left in the central areas due to their limited ability to afford better housing units, vehicles, and longer travel. However, many commercial parcels (e.g., retails and restaurants) remain and cluster in central areas, and the dispersed suburban developments are dominated by residential uses and generally separated from commercial locations (Páez et al. 2010). Therefore, our finding of the accessibility for low-income people is consistent with these distribution patterns. It is also reasonable to find that medium- and high-income people have lower accessibility to industrial parcels because they prefer to and are able to afford to live away from these parcels, where most hazardous operations, such as power plants and toxic waste sites, are located (Laurian and Funderburg 2014; Faber and Krieg 2002).

As another focus of the statistical modeling in this study, the built environment is represented by transit stop density, seven new neighborhood clusters constructed through $K$-means cluster analysis, and a job-population balance index. Living in areas with higher transit stop density is positively and directly associated with accessibility to different opportunities. This association is relatively strong as compared to most socio-demographic variables by looking at the values of standardized effects. In all path models, most clusters indicate significant and strong effects on average trip distance and accessibility in expected directions. Cluster 7 is the reference cluster, which refers to low-density single-family neighborhoods. As compared to Cluster 7, people travel shorter distances if living in TAZs characterized by urban features (e.g., higher densities, mixed uses, and a lower percentage of single-family, detached houses). The signs of direct effects from clusters on accessibility suggest that residing in an urban setting increases people's number of opportunities per square mile available within their daily activity spaces. In particular, the standardized values indicate that when people live closer to more urbanized areas (e.g., Clusters 1 and 3), the effects are stronger. In addition, the built environment is described by a job-population balance index, representing a balance of employment and population in each residential location TAZ. Zero indicates that there are only employment or population in that TAZ; one represents a well-mixed population and employment. Being consistent with the findings on transit proximity and new neighborhood types, increasing this balance decreases average trip distance and increases accessibility to most opportunities. These expected effects of the built environment on accessibility and trip distance support smart-growth policies, which advocate compact development to increase activity participation and quality of life for different groups of people.

Overall, the magnitude of total effects on accessibility from significant exogenous variables is somehow changed through the indirect effects from average trip distance. For example, the total effects of the job-population balance on accessibility to industrial use and jobs are weakened through the negative indirect effects, while reinforced for retail jobs with a positive indirect effect. These mixed effects from the same variables on different types of accessibility in this study suggest to policymakers the importance of disaggregating accessibility for transport exclusion analysis. 
Table 5: Path model results for accessibility to land uses (standardized effects)

\begin{tabular}{|c|c|c|c|c|c|c|}
\hline & \multicolumn{5}{|c|}{ Land Uses } & \multirow[b]{2}{*}{$\begin{array}{c}\text { ln (Average trip } \\
\text { distance) }\end{array}$} \\
\hline & Effect & Total & Commercial & Office & Industrial & \\
\hline Intercept & & 71.483 & 59.221 & 3.011 & 11.502 & 1.144 \\
\hline \multicolumn{7}{|c|}{ Trip Characteristics } \\
\hline \multirow{3}{*}{$\begin{array}{c}\ln \text { (Average trip } \\
\text { distance) }\end{array}$} & Total & .007 & -.056 & -.013 & .105 & - \\
\hline & Direct & {$[.007]$} & -.056 & {$[-.013]$} & .105 & - \\
\hline & Indirect & - & - & - & - & - \\
\hline \multirow{3}{*}{ Auto use } & Total & -.032 & -.039 & -.053 & .018 & .167 \\
\hline & Direct & -.033 & -.030 & -.051 & - & .167 \\
\hline & Indirect & .001 & -.009 & -.002 & .018 & - \\
\hline \multicolumn{7}{|c|}{ Socio-Demographics } \\
\hline \multicolumn{7}{|c|}{ Age (Base: 36 to 50 years) } \\
\hline \multirow{3}{*}{19 or younger } & Total & -.045 & -.044 & -.002 & -.052 & -.025 \\
\hline & Direct & -.045 & -.045 & {$[-.003]$} & -.049 & -.025 \\
\hline & Indirect & .000 & .001 & .000 & -.003 & - \\
\hline \multirow{3}{*}{20 to 35 years } & Total & -.005 & -.011 & .030 & -.005 & -.025 \\
\hline & Direct & {$[-.005]$} & {$[-.012]$} & .029 & {$[-.002]$} & -.025 \\
\hline & Indirect & .000 & .001 & .000 & -.003 & - \\
\hline \multirow{3}{*}{51 to 64 years } & Total & -.010 & -.011 & -.006 & -.002 & -.044 \\
\hline & Direct & {$[-.010]$} & {$[-.013]$} & {$[-.007]$} & {$[.002]$} & -.044 \\
\hline & Indirect & .000 & .002 & .001 & -.005 & - \\
\hline \multirow{3}{*}{65 years or older } & Total & -.065 & -.056 & -.014 & -.066 & -.072 \\
\hline & Direct & -.065 & -.060 & {$[-.015]$} & -.058 & -.072 \\
\hline & Indirect & .000 & .004 & .001 & -.007 & - \\
\hline \multirow{3}{*}{ License status } & Total & .000 & -.028 & .000 & .003 & .028 \\
\hline & Direct & - & -.027 & - & - & .028 \\
\hline & Indirect & .000 & -.002 & .000 & .003 & - \\
\hline \multirow{3}{*}{ Female } & Total & -.025 & .003 & .001 & -.044 & -.048 \\
\hline & Direct & -.025 & - & - & -.039 & -.048 \\
\hline & Indirect & - & .003 & .001 & -.005 & - \\
\hline \multirow{3}{*}{ Race } & Total & .167 & .149 & .043 & .153 & - \\
\hline & Direct & .167 & .149 & .043 & .153 & - \\
\hline & Indirect & - & - & - & - & - \\
\hline \multirow{3}{*}{ Education } & Total & .000 & -.002 & .050 & .003 & .031 \\
\hline & Direct & - & - & .051 & - & .031 \\
\hline & Indirect & .000 & -.002 & .000 & .003 & - \\
\hline \multirow{3}{*}{ Employee } & Total & .001 & -.010 & .044 & .018 & .171 \\
\hline & Direct & - & - & .047 & - & .171 \\
\hline & Indirect & .001 & -.010 & -.002 & .018 & - \\
\hline
\end{tabular}


Table 5: Path model results for accessibility to land uses (standardized effects) (continued)

\begin{tabular}{|c|c|c|c|c|c|c|}
\hline & \multicolumn{5}{|c|}{ Land Uses } & \multirow[b]{2}{*}{$\begin{array}{l}\ln \text { (Average trip } \\
\text { distance) }\end{array}$} \\
\hline & Effect & Total & Commercial & Office & Industrial & \\
\hline \multicolumn{7}{|c|}{ Income (Base: low income) } \\
\hline \multirow{3}{*}{$\begin{array}{c}\text { Medium- income } \\
\text { group }\end{array}$} & Total & -.090 & -.084 & -.001 & -.077 & .103 \\
\hline & Direct & -.091 & -.078 & - & -.088 & .103 \\
\hline & Indirect & .001 & -.006 & -.001 & .011 & - \\
\hline \multirow{3}{*}{$\begin{array}{l}\text { High-income } \\
\text { group }\end{array}$} & Total & -.073 & -.071 & -.001 & -.063 & .087 \\
\hline & Direct & -.074 & -.066 & - & -.073 & .087 \\
\hline & Indirect & .001 & -.005 & -.001 & .009 & - \\
\hline \multirow{3}{*}{ Household head } & Total & .000 & .002 & .000 & -.003 & -.029 \\
\hline & Direct & - & - & - & - & -.029 \\
\hline & Indirect & .000 & .002 & .000 & -.003 & - \\
\hline \multirow{3}{*}{$\begin{array}{l}\text { Vehicles per } \\
\text { driver }\end{array}$} & Total & - & - & -.027 & - & - \\
\hline & Direct & - & - & -.027 & - & - \\
\hline & Indirect & - & - & - & - & - \\
\hline \multirow{3}{*}{ Household size } & Total & .000 & .004 & -.062 & .019 & -.069 \\
\hline & Direct & - & - & -.063 & .026 & -.069 \\
\hline & Indirect & .000 & .004 & .001 & -.007 & - \\
\hline \multirow{3}{*}{ Presence of retiree } & Total & .000 & .002 & .001 & -.004 & -.039 \\
\hline & Direct & - & - & - & - & -.039 \\
\hline & Indirect & .000 & .002 & .001 & -.004 & - \\
\hline \multirow{3}{*}{$\begin{array}{c}\text { Presence of } \\
\text { another worker }\end{array}$} & Total & .000 & .002 & .001 & -.032 & -.042 \\
\hline & Direct & - & - & - & -.027 & -.042 \\
\hline & Indirect & .000 & .002 & .001 & -.004 & - \\
\hline \multicolumn{7}{|c|}{ Residential Location Characteristics (Built Environment) } \\
\hline \multirow{3}{*}{$\begin{array}{c}\text { Transit stop } \\
\text { density }\end{array}$} & Total & .150 & .130 & .128 & .128 & - \\
\hline & Direct & .150 & .130 & .128 & .128 & - \\
\hline & Indirect & - & - & - & - & - \\
\hline \multirow{3}{*}{ JOBPOP } & Total & .018 & .003 & .040 & .023 & -.055 \\
\hline & Direct & .018 & - & .039 & .029 & -.055 \\
\hline & Indirect & .000 & .003 & .001 & -.006 & - \\
\hline \multicolumn{7}{|c|}{ Cluster Indicators (Neighborhood Types; Base: Cluster 7) } \\
\hline \multirow{3}{*}{ Cluster 1} & Total & .253 & .292 & .108 & .128 & -.093 \\
\hline & Direct & .253 & .286 & .107 & .138 & -.093 \\
\hline & Indirect & -.001 & .005 & .001 & -.010 & - \\
\hline \multirow{3}{*}{ Cluster 3} & Total & .304 & .325 & .133 & .193 & -.119 \\
\hline & Direct & .304 & .318 & .131 & .206 & -.119 \\
\hline & Indirect & -.001 & .007 & .002 & -.012 & - \\
\hline \multirow{3}{*}{ Cluster 4} & Total & .111 & .126 & .065 & .054 & -.085 \\
\hline & Direct & .111 & .122 & .064 & .063 & -.085 \\
\hline & Indirect & -.001 & .005 & .001 & -.009 & - \\
\hline
\end{tabular}


Table 5: Path model results for accessibility to land uses (standardized effects) (continued)

\begin{tabular}{|c|c|c|c|c|c|c|}
\hline & \multicolumn{5}{|c|}{ Land Uses } & \multirow[b]{2}{*}{$\begin{array}{l}\ln \text { (Average trip } \\
\text { distance) }\end{array}$} \\
\hline & Effect & Total & Commercial & Office & Industrial & \\
\hline \multirow{3}{*}{ Cluster 5} & Total & .104 & .103 & .103 & .069 & -.005 \\
\hline & Direct & .104 & .103 & .103 & .069 & {$[-.005]$} \\
\hline & Indirect & .000 & .000 & .000 & -.001 & - \\
\hline \multirow{3}{*}{ Cluster 6} & Total & .032 & .048 & .033 & -.004 & -.056 \\
\hline & Direct & .032 & .045 & .032 & {$[.002]$} & -.056 \\
\hline & Indirect & .000 & .003 & .001 & -.006 & - \\
\hline \multicolumn{7}{|c|}{ County indicators (Base: Cuyahoga County) } \\
\hline \multirow{3}{*}{ Geauga } & Total & -.040 & -.042 & .015 & -.034 & .047 \\
\hline & Direct & -.041 & -.040 & {$[.016]$} & -.039 & .047 \\
\hline & Indirect & .000 & -.003 & -.001 & .005 & - \\
\hline \multirow{3}{*}{ Lake } & Total & .069 & .039 & .123 & .077 & .028 \\
\hline & Direct & .069 & .041 & .123 & .074 & .028 \\
\hline & Indirect & .000 & -.002 & .000 & .003 & - \\
\hline \multirow{3}{*}{ Lorain } & Total & .031 & .053 & .195 & -.051 & .013 \\
\hline & Direct & .031 & .054 & .195 & -.053 & {$[.013]$} \\
\hline & Indirect & .000 & -.001 & .000 & .001 & - \\
\hline \multirow{3}{*}{ Medina } & Total & .007 & .042 & -.021 & -.042 & -.005 \\
\hline & Direct & {$[.007]$} & .042 & -.021 & -.042 & {$[-.005]$} \\
\hline & Indirect & .000 & .000 & .000 & -.001 & - \\
\hline \multicolumn{7}{|l|}{ Model Fit } \\
\hline Chi-Square & & 11.093 & 8.758 & 13.329 & 8.242 & \\
\hline (p-value) & & $(.852)$ & $(.965)$ & $(.649)$ & $(.941)$ & \\
\hline RMSEA & & .000 & .000 & .000 & .000 & \\
\hline CFI & & 1.000 & 1.000 & 1.000 & 1.000 & \\
\hline AIC & & 1165.09 & 1160.76 & 1169.33 & 1164.24 & \\
\hline
\end{tabular}

Number of observations: 5929

[ ]: Not significant ( $\mathrm{p}$-value $>0.1$; only for categorical variables, if at least one category is significant at the 0.1 level)

-: Dropped due to insignificance ( $\mathrm{p}$-value $>0.1$ ) for direct effect; no indirect effect 
Table 6: Path model results for accessibility to jobs (standardized effects)

\begin{tabular}{|c|c|c|c|c|c|c|}
\hline & \multicolumn{5}{|c|}{ Jobs } & \multirow[b]{2}{*}{$\begin{array}{c}\ln \text { (Average trip } \\
\text { distance) }\end{array}$} \\
\hline & Effect & Total & Retail & Office & Industrial & \\
\hline Intercept & & 1694.955 & 674.511 & 1078.074 & 273.856 & 1.144 \\
\hline \multicolumn{7}{|c|}{ Trip Characteristics } \\
\hline \multirow{3}{*}{$\begin{array}{l}\text { In (Average trip } \\
\text { distance) }\end{array}$} & Total & -.003 & -.054 & .004 & .039 & - \\
\hline & Direct & {$[-.003]$} & -.054 & {$[.004]$} & .039 & - \\
\hline & Indirect & - & - & - & - & - \\
\hline \multirow{3}{*}{ Auto use } & Total & -.045 & -.009 & -.047 & .007 & .167 \\
\hline & Direct & -.045 & - & -.048 & - & .167 \\
\hline & Indirect & .000 & -.009 & .001 & .007 & - \\
\hline \multicolumn{7}{|c|}{ Socio-Demographics } \\
\hline \multicolumn{7}{|c|}{ Age (Reference Group: 36 to 50 years) } \\
\hline \multirow{3}{*}{19 or younger } & Total & .002 & .001 & .000 & -.031 & -.025 \\
\hline & Direct & {$[.002]$} & - & - & -.030 & -.025 \\
\hline & Indirect & .000 & .001 & .000 & -.001 & - \\
\hline \multirow{3}{*}{20 to 35 years } & Total & .032 & .001 & .000 & .041 & -.025 \\
\hline & Direct & .032 & - & - & .042 & -.025 \\
\hline & Indirect & .000 & .001 & .000 & -.001 & - \\
\hline \multirow{3}{*}{51 to 64 years } & Total & -.007 & .002 & .000 & -.027 & -.044 \\
\hline & Direct & {$[-.007]$} & - & - & -.025 & -.044 \\
\hline & Indirect & .000 & .002 & .000 & -.002 & - \\
\hline \multirow{3}{*}{65 years or older } & Total & -.011 & .004 & .000 & -.060 & -.072 \\
\hline & Direct & {$[-.011]$} & - & - & -.057 & -.072 \\
\hline & Indirect & .000 & .004 & .000 & -.003 & - \\
\hline \multirow{3}{*}{ License status } & Total & .000 & -.002 & -.025 & .001 & .028 \\
\hline & Direct & - & - & -.026 & - & .028 \\
\hline & Indirect & .000 & -.002 & .000 & .001 & - \\
\hline \multirow{3}{*}{ Female } & Total & .000 & .003 & .000 & -.054 & -.048 \\
\hline & Direct & - & - & - & -.052 & -.048 \\
\hline & Indirect & .000 & .003 & .000 & -.002 & - \\
\hline \multirow{3}{*}{ Race } & Total & - & - & .029 & - & - \\
\hline & Direct & - & - & .029 & - & - \\
\hline & Indirect & - & - & - & - & - \\
\hline \multirow{3}{*}{ Education } & Total & .000 & -.002 & .028 & .001 & .031 \\
\hline & Direct & - & - & .028 & - & .031 \\
\hline & Indirect & .000 & -.002 & .000 & .001 & - \\
\hline \multirow{3}{*}{ Employee } & Total & .074 & -.009 & .082 & .007 & .171 \\
\hline & Direct & .075 & - & .081 & - & .171 \\
\hline & Indirect & .000 & -.009 & .001 & .007 & - \\
\hline
\end{tabular}


Table 6: Path model results for accessibility to jobs (standardized effects) (continued)

\begin{tabular}{|c|c|c|c|c|c|c|}
\hline & \multicolumn{5}{|c|}{ Jobs } & \multirow[b]{2}{*}{$\begin{array}{c}\ln \text { (Average trip } \\
\text { distance) }\end{array}$} \\
\hline & Effect & Total & Commercial & Office & Industrial & \\
\hline \multicolumn{7}{|c|}{ Income (Base: low income) } \\
\hline \multirow{3}{*}{$\begin{array}{l}\text { Medium-income } \\
\text { group }\end{array}$} & Total & .011 & -.006 & .012 & .004 & .103 \\
\hline & Direct & {$[.012]$} & - & {$[.012]$} & - & .103 \\
\hline & Indirect & .000 & -.006 & .000 & .004 & - \\
\hline \multirow{3}{*}{$\begin{array}{l}\text { High-income } \\
\text { group }\end{array}$} & Total & .039 & -.005 & .042 & .003 & .087 \\
\hline & Direct & .039 & - & .042 & - & .087 \\
\hline & Indirect & .000 & -.005 & .000 & .003 & - \\
\hline \multirow{3}{*}{ Household head } & Total & .000 & .002 & .000 & -.001 & -.029 \\
\hline & Direct & - & - & - & - & -.029 \\
\hline & Indirect & .000 & .002 & .000 & -.001 & - \\
\hline \multirow{3}{*}{ Household size } & Total & -.037 & -.031 & -.028 & -.031 & -.069 \\
\hline & Direct & -.037 & -.034 & -.028 & -.028 & -.069 \\
\hline & Indirect & .000 & .004 & .000 & -.003 & - \\
\hline \multirow{3}{*}{ Presence of retiree } & Total & .000 & -.024 & .000 & -.002 & -.039 \\
\hline & Direct & - & -.026 & - & - & -.039 \\
\hline & Indirect & .000 & .002 & .000 & -.002 & - \\
\hline \multirow{3}{*}{$\begin{array}{c}\text { Presence of } \\
\text { another worker }\end{array}$} & Total & -.043 & .002 & -.044 & -.002 & -.042 \\
\hline & Direct & -.043 & - & -.044 & - & -.042 \\
\hline & Indirect & .000 & .002 & .000 & -.002 & - \\
\hline \multicolumn{7}{|c|}{ Residential Location Characteristics (Built Environment) } \\
\hline \multirow{3}{*}{$\begin{array}{c}\text { Transit stop } \\
\text { density }\end{array}$} & Total & .169 & .035 & .180 & .033 & - \\
\hline & Direct & .169 & .035 & .180 & .033 & - \\
\hline & Indirect & - & - & - & - & - \\
\hline \multirow{3}{*}{ JOBPOP } & Total & .030 & .038 & .000 & .041 & -.055 \\
\hline & Direct & .030 & .035 & - & .043 & -.055 \\
\hline & Indirect & .000 & .003 & .000 & -.002 & - \\
\hline \multicolumn{7}{|c|}{ Cluster indicators (Neighborhood Types; Base: Cluster 7) } \\
\hline \multirow{3}{*}{ Cluster 1} & Total & .082 & .026 & .061 & .118 & -.093 \\
\hline & Direct & .082 & {$[.021]$} & .061 & .122 & -.093 \\
\hline & Indirect & .000 & .005 & .000 & -.004 & - \\
\hline \multirow{3}{*}{ Cluster 3} & Total & .069 & -.025 & .065 & .070 & -.119 \\
\hline & Direct & .069 & -.031 & .065 & .075 & -.119 \\
\hline & Indirect & .000 & .006 & .000 & -.005 & - \\
\hline \multirow{3}{*}{ Cluster 4} & Total & .020 & -.013 & .016 & .059 & -.085 \\
\hline & Direct & {$[.020]$} & {$[-.018]$} & {$[.017]$} & .063 & -.085 \\
\hline & Indirect & .000 & .005 & .000 & -.003 & - \\
\hline
\end{tabular}


Table 6: Path model results for accessibility to jobs (standardized effects) (continued)

\begin{tabular}{|c|c|c|c|c|c|c|}
\hline & \multicolumn{5}{|c|}{ Jobs } & \multirow[b]{2}{*}{$\begin{array}{c}\ln \text { (Average trip } \\
\text { distance) }\end{array}$} \\
\hline & Effect & Total & Commercial & Office & Industrial & \\
\hline \multirow{3}{*}{ Cluster 5} & Total & .067 & .047 & .049 & .071 & -.005 \\
\hline & Direct & .067 & .047 & .049 & .071 & {$[-.005]$} \\
\hline & Indirect & .000 & .000 & .000 & .000 & - \\
\hline \multirow{3}{*}{ Cluster 6} & Total & -.002 & -.003 & .000 & .005 & -.056 \\
\hline & Direct & {$[-.002]$} & {$[-.006]$} & {$[.000]$} & {$[.008]$} & -.056 \\
\hline & Indirect & .000 & .003 & .000 & -.002 & - \\
\hline \multicolumn{7}{|c|}{ County Indicators (Base: Cuyahoga County) } \\
\hline \multirow{3}{*}{ Geauga } & Total & -.049 & -.091 & -.023 & -.045 & .047 \\
\hline & Direct & -.048 & -.088 & -.023 & -.047 & .047 \\
\hline & Indirect & .000 & -.003 & .000 & .002 & - \\
\hline \multirow{3}{*}{ Lake } & Total & -.017 & -.057 & -.010 & .049 & .028 \\
\hline & Direct & {$[-.017]$} & -.056 & {$[-.010]$} & .048 & .028 \\
\hline & Indirect & .000 & -.002 & .000 & .001 & - \\
\hline \multirow{3}{*}{ Lorain } & Total & -.061 & -.106 & -.028 & -.066 & .013 \\
\hline & Direct & -.061 & -.106 & -.028 & -.066 & {$[.013]$} \\
\hline & Indirect & .000 & -.001 & .000 & .001 & - \\
\hline \multirow{3}{*}{ Medina } & Total & -.036 & -.059 & -.015 & -.045 & -.005 \\
\hline & Direct & -.036 & -.060 & {$[-.015]$} & -.045 & {$[-.005]$} \\
\hline & Indirect & .000 & .000 & .000 & .000 & - \\
\hline \multicolumn{7}{|l|}{ Model Fit } \\
\hline Chi-Square & & 11.329 & 17.457 & 9.522 & 15.934 & \\
\hline (p-value) & & $(0.789)$ & $(0.829)$ & $(0.946)$ & $(0.721)$ & \\
\hline RMSEA & & .000 & .000 & .000 & .000 & \\
\hline CFI & & 1.000 & 1.000 & 1.000 & 1.000 & \\
\hline AIC & & 1167.33 & 1157.46 & 1161.52 & 1163.93 & \\
\hline
\end{tabular}

Number of observations: 5929

[ ]: Not significant (p-value > 0.1; only for categorical variables, if at least one category is significant at the 0.1 level)

-: Dropped due to insignificance ( $\mathrm{p}$-value $>0.1$ ) for direct effect; no indirect effect

\section{Conclusions}

This study applies the Capability Approach as an equality framework to define and measure transport-related social exclusion. Our research thus develops individual accessibility based on daily activity space as a transport exclusion indicator. Individual accessibility controlling for the size of activity spaces through the cumulative-opportunity approach is calculated for parcel-level land uses (commercial, office, and industrial) and block-level jobs (retail, office, and industrial j) using data from the Greater Cleveland region, Ohio.

The accessibility comparison results among low-, medium- and high-income groups suggest that 
low-income people in the sample are not at a disadvantage in terms of opportunities per square mile within their own activity spaces. Furthermore, this study applies path analysis to examine the relationships between socio-demographics, built environment, trip characteristics, and individual accessibility. This modeling approach decomposes total effects into direct and indirect effects, and thus we can better understand these relationships.

The path models present three major findings. First, the effects of average trip distances on individual accessibility vary across different types of opportunities. As a mediating variable, it influences the total effects of exogenous variables on accessibility through changing either the signs or the magnitude.

Second, the effects of some socio-demographic characteristics on accessibility raise some social equity concerns. For example, all else being equal, adolescents and elderly have lower accessibility to commercial and industrial uses and industrial jobs. Individuals in households with income lower than $\$ 30,000$ access fewer office jobs. Although these findings identify the transport disadvantage status of some socially excluded groups based on accessibility to some categories of opportunities, those groups are not always disadvantaged when examining their accessibility to other categories. This calls for policymakers to pay attention to considering the disaggregation of accessibility, which is used to evaluate the social issues of transportation investments and projects.

The $K$-means cluster analysis is used to construct seven neighborhood types for better understanding the effect of built environment on accessibility. The results suggest that living in neighborhoods characterized with urban features in terms of high densities, mixed uses, and fewer single-family, detached housing units decreases people's average trip distance and increases their accessibility significantly. Consistently, the job-population balance and transit proximity affect accessibility in the same directions as neighborhood types. These significant results provide meaningful insights that suggest decision makers should consider the effect of built environment from a comprehensive perspective instead of only looking at land-use features individually.

This research is not without limitations. First, our ability to deal with the residential self-selection is limited since we do not have individual panel data or any attitudinal variables. The second major limitation is the restricted use of the geographical coordinates of the locations. The calculations of individual accessibility and activity space could have been more accurate if we had known this information. In our future research, we could also improve the accuracy of calculating accessibility if we account for the impedance (e.g., distance decay) of reaching opportunities by recognizing that the far and close opportunities within the determined catchment area are different.

Another limitation is that the analysis of job accessibility in this study does not discuss spatial mismatch, which relates to job decentralization and housings segregation. The hypothesis of spatial mismatch implies that entry-level jobs (low educational requirements) with relatively low wages have been spreading out from inner cities where most low-income people reside (Ihlanfeldt 1994). Most jobs within central urban districts are related to information-processing (e.g., office jobs), requiring relatively higher educational backgrounds. It often restricts low-income people from acquiring these nearby jobs and building up their social network. This study focuses on the examination of different social groups' potential spatial access to three categories of jobs without specifying the quality and qualification of jobs. Considering the suitability of jobs for different social groups would improve the analysis of job accessibility and may be the focus of future research.

\section{Acknowledgements}

The authors would like to sincerely thank Dr. Philip A. Viton for his help and support on this research paper, Ms. Rebekah Anderson of ODOT for providing the datasets, and three anonymous reviewers for their critical comments on an earlier version of the paper. 


\section{References}

Akar, G., N. Chen, and S. I. Gordon. 2016. Influence of neighborhood types on trip distances: Spatial error models for Central Ohio. International Journal of Sustainable Transportation 10(3): 284-293. doi: 10.1080/15568318.2014.903447.

Aldenderfer, M. S., and R. K. Blashfield. 1984. Cluster Analysis. Sage University Paper Series On Quantitative Applications in the Social Sciences 07-044. http://dx.doi.org/10.4135/9781412983648

Atkins. 2012. Accessibility Planning Policy: Evaluation and Future Directions. Final report. https://www. gov.uk/government/uploads/system/uploads/attachment_data/file/3190/accessibility-planningevaluation-report.pdf.

Barber, C. B., D. P. Dobkin, and H. Huhdanpaa. 1996. The quickhull algorithm for convex hulls. $A C M$ Transactions on Matematical Software 22(4): 469-483. doi: 10.1145/235815.235821.

Bertolini, L., F. le Clercq, and L. Kapoen. 2005. Sustainable accessibility: A conceptual framework to integrate transport and land-use plan-making. Two test-applications in the Netherlands and a reflection on the way forward. Transport Policy 12(3): 207-220. doi: http://dx.doi.org/10.1016/j. tranpol.2005.01.006.

Beyazit, E. 2011. Evaluating social justice in transport: Lessons to be learned from the capability approach. Transport Reviews 31(1): 117-134.

Blunch, N. J. 2008. Introduction to structural equation modelling using SPSS and AMOS. London, UK: Sage.

Bocarejo S. J. P., and D. R. Oviedo. 2012. Transport accessibility and social inequities: A tool for identification of mobility needs and evaluation of transport investments. Journal of Transport Geography 24: 142-154.

Burns, L. D. 1979. Transportation, Temporal, and Spatial Components of accessibility. Lexington, MA: Lexington Books.

Casas, I. 2007. Social exclusion and the disabled: An accessibility approach. The Professional Geographer 59(4): 463-477.

Casas, I., M. W. Horner, and J. Weber. 2009. A comparison of three methods for identifying transportbased exclusion: A case study of children's access to urban opportunities in Erie and Niagara Counties, New York. International Journal of Sustainable Transportation 3(4): 227-245.

Cervero, R., and K. Kockelman. 1997. Travel demand and the 3Ds: Density, diversity, and design. Transportation Research Part D: Transport and Environment 2(3): 199-219.

Chen, N., and G. Akar. 2016. Effects of neighborhood types and socio-demographics on activity space. Journal of Transport Geography 54: 112-121. doi: http://dx.doi.org/10.1016/j.jtrangeo.2016.05.017.

Clark, D. A. 2005. The capability approach: Its development, critiques and recent advances. Oxford, UK: University of Oxford, Department of Economics.

Clifton, K. J., K. M. Currans, A. C. Cutter, and R. Schneider. 2012. Household travel surveys in context-based approach for adjusting ITE trip generation rates in urban contexts. Transportation Research Record 2307(1): 108-119.

Collia, D. V., J. Sharp, and L. Giesbrecht. 2003. The 2001 national household travel survey: A look into the travel patterns of older Americans. Journal of Safety Research 34(4): 461-470.

Delmelle, E. C., and I. Casas. 2012. Evaluating the spatial equity of bus rapid transit-based accessibility patterns in a developing country: The case of Cali, Colombia. Transport Policy 20:36-46. doi: http:// dx.doi.org/10.1016/j.tranpol.2011.12.001.

Ewing, R., and R. Cervero. 2010. Travel and the built environment: A meta-analysis. Journal of the American Planning Association 76(3): 265-294. 
Ewing, R., M. Greenwald, M. Zhang, J. Walters, M. Feldman, R. Cervero, L. Frank, and J. Thomas. 2011. Traffic generated by mixed-use developments—-six-region study using consistent built environmental measures. Journal of Urban Planning and Development 137(3): 248-261.

Exner, R. 2015. Census estimates show Greater Cleveland population down slightly 2015. http://www. cleveland.com/datacentral/index.ssf/2013/03/census_estimates_show_greater.html.

Faber, D. R., and E. J. Krieg. 2002. Unequal exposure to ecological hazards: Environmental injustices in the Commonwealth of Massachusetts. Environmental Health Perspectives 110(S2): 277-288.

Fan, Y., A. Guthrie, and D. Levinson. 2012. Impact of light rail implementation on labor market accessibility: A transportation equity perspective. Journal of Transport and Land Use 5 (3): 28-39.

Geurs, K. T., K. J. Krizek, and A. Reggiani. 2012. Accessibility analysis and transport planning: challenges for Europe and North America. Cheltenham, UK: Edward Elgar Publishing.

Geurs, K. T., and B. van Wee. 2004. Accessibility evaluation of land-use and transport strategies: Review and research directions. Journal of Transport Geography 12(2): 127-140. doi: http://dx.doi. org/10.1016/j.jtrangeo.2003.10.005.

Gilbert, R., N. Irwin, B. Hollingworth, and P. Blais. 2002. Sustainable Transportation Performance Indicators (STPI) Projects. In Reports on Phase 3: CSTCTD. http://www.ltrc.lsu.edu/TRB_82/ TRB2003-001700.pdf.

Golledge, R. G. 1997. Spatial Behavior: A Geographic Perspective. New York: Guilford Press.

Golob, T. F. 2003. Structural equation modeling for travel behavior research. Transportation Research Part B: Methodological 37(1): 1-25.

Hägerstraand, T. 1970. What about people in regional science? Papers in Regional Science 24(1): 7-24.

Halden, D. 2014. Shaping the future: Case studies in UK accessibility planning. Transportation Research Procedia 1(1): 284-292. doi: http://dx.doi.org/10.1016/j.trpro.2014.07.028.

Handy, S. L. 2002. Accessibility- vs. mobility-enhancing strategies for addressing automobile dependence in the U.S. Institute of Transportation Studies, University of California at Davis. http://www. des.ucdavis.edu/faculty/handy/ECMT_report.pdf.

Hansen, W. G. 1959. How accessibility shapes land use. Journal of the American Institute of Planners 25(2): 73-76.

Harding, C., Z. Patterson, L. F. Miranda-Moreno, and S. A. H. Zahabi. 2012. Modeling the effect of land use on activity spaces. Transportation Research Record 2323(1): 67-74.

Horton, F. E., and D. R. Reynolds. 1971. Effects of urban spatial structure on individual behavior. Economic Geography 47(1): 36-48. doi: 10.2307/143224.

Ihlanfeldt, K. 1994. The spatial mismatch between jobs and residential locations within urban areas. Cityscape 1(1): 219-244.

Kamruzzaman, M., and J. Hine. 2012. Analysis of rural activity spaces and transport disadvantage using a multi-method approach. Transport Policy 19(1): 105-120.

Kawabata, M., and Q. Shen. 2006. Job accessibility as an indicator of auto-oriented urban structure: A comparison of Boston and Los Angeles with Tokyo. Environment and Planning B: Planning and Design 33(1): 115-130.

Kenyon, S., G. Lyons, and J. Rafferty. 2002. Transport and social exclusion: Investigating the possibility of promoting inclusion through virtual mobility. Journal of Transport Geography 10(3): 207-219.

Kim, H.-M., and M.-P. Kwan. 2003. Space-time accessibility measures: A geocomputational algorithm with a focus on the feasible opportunity set and possible activity duration. Journal of Geographical Systems 5(1): 71-91.

Kockelman, K. 1997. Travel behavior as function of accessibility, land-use mixing, and land-use balance: Evidence from San Francisco Bay Area. Transportation Research Record 1607: 116-125. 
Krizek, K. J. 2003. Residential relocation and changes in urban travel: Does neighborhood-scale urban form matter? Journal of the American Planning Association 69(3): 265-281.

Kwan, M.-P. 1999. Gender and individual access to urban opportunities: A study using space-time measures. The Professional Geographer 51(2): 211-227. doi: 10.1111/0033-0124.00158.

Laurian, L., and R. Funderburg. 2014. Environmental justice in France? A spatio-temporal analysis of incinerator location. Journal of Environmental Planning and Management 57 (3): 424-446.

Lefkowitz, M. 2015. 4-7-2015. Cleveland: Dead last in controlling jobs sprawl. In GreenCityBlueLake Blog. http://www.gcbl.org/blog/2015/04/cleveland-dead-last-in-controlling-jobs-sprawl.

Levine, J., J. Grengs, Q. Shen, and Q. Shen. 2012. Does accessibility require density or speed? A comparison of fast versus close in getting where you want to go in US metropolitan regions. Journal of the American Planning Association 78(2): 157-172.

Litman, T. 2002. Evaluating transportation equity. World Transport Policy and Practice 8(2): 50-65.

Litman, T., and M. Brenman. 2012. A new social equity agenda for sustainable transportation. Victoria, BC, Canada: Victoria Transport Policy Institute.

Lubin, A., and D. Deka. 2012. Role of public transportation as job access mode. Transportation Research Record 2277(1): 90-97.

Lucas, K., G. Marsden, M. Brooks, and M. Kimble. 2007. Assessment of capabilities for examining long-term social sustainability of transport and land-use strategies. Transportation Research Record 2013(1): 30-37.

Manaugh, K., and A. El-Geneidy. 2012. What makes travel local: Defining and understanding local travel behavior. Journal of Transport and Land Use 5(3): 15-27.

Manaugh, K., L. F. Miranda-Moreno, and A. M. El-Geneidy. 2010. The effect of neighborhood characteristics, accessibility, home-work location, and demographics on commuting distances. Transportation 37(4): 627-646. doi: 10.1007/s11116-010-9275-z.

Neutens, T., T. Schwanen, F. Witlox, and P. De Maeyer. 2010. Equity of urban service delivery: A comparison of different accessibility measures. Environment and Planning A 42(7): 1613.

Niemeier, D. A. 1997. Accessibility: An evaluation using consumer welfare. Transportation 24(4): 377396.

Páez, A., R. G. Mercado, S. Farber, C. Morency, and M. Roorda. 2010. Relative accessibility deprivation indicators for urban settings: Definitions and application to food deserts in Montreal. Urban Studies 47(7): 1415-1438. doi: 10.1177/0042098009353626.

Páez, A., D. M. Scott, and C. Morency. 2012. Measuring accessibility: Positive and normative implementations of various accessibility indicators. Journal of Transport Geography 25: 141-153.

Pang-Ning, T., M. Steinbach, and V. Kumar. 2006. Introduction to data mining. Paper read at Library of Congress.

Preston, J., and F. Rajé. 2007. Accessibility, mobility and transport-related social exclusion. Journal of Transport Geography 15(3): 151-160.

Pritchard, J. P., F. Moura, J. d. A. e Silva, and L. M. Martinez. 2014. Spatial analysis of transportationrelated social exclusion in the Lisbon metropolitan area. Procedia-Social and Behavioral Sciences 111: 440-449.

Rashid, K., T. Yigitcanlar, and J. M. Bunker. 2010. Minimizing transport disadvantage to support knowledge city formation: Applying the capability approach to select indicators. Melbourne: The 3rd Knowledge Cities World Summit.

Robeyns, I. 2006. The capability approach in practice. Journal of Political Philosophy 14(3): 351-376.

Schönfelder, S., and K. W. Axhausen. 2003. Activity spaces: Measures of social exclusion? Transport Policy 10(4): 273-286. doi: http://dx.doi.org/10.1016/j.tranpol.2003.07.002. 
Schumacker, R. E., and R. G. Lomax. 2004. A Beginner's Guide to Structural Equation Modeling. Oxfordshire, UK: Taylor and Fraincis, Psychology Press.

Sen, A. 1980. Equality of what? In Tanner Lectures on Human Values, Volume 1, edited by S. McMurrin. Cambridge, UK: Cambridge University Press.

Shen, Q. 1998. Location characteristics of inner-city neighborhoods and employment accessibility of low-wage workers. Environment and Planning B: Planning and Design 25(3): 345-365.

Sherman, J. E., J. Spencer, J. Preisser, W. Gesler, and T. Arcury. 2005. A suite of methods for representing activity space in a healthcare accessibility study. International Journal of Health Geographics 4(1): 1-21. doi: 10.1186/1476-072X-4-24.

Smith, N., D. Hirsch, and A. Davis. 2012. Accessibility and capability: The minimum transport needs and costs of rural households. Journal of Transport Geography 21: 93-101.

Social Exclusion Unit, Office of the Deputy Prime Minister. 2003. Making the Connections: Final Report on Transport and Social Exclusion.http://www.ilo.org/wcmsp5/groups/public/@ed_emp/@emp_policy/@ invest/documents/publication/woms_asist_8210.pdf.

Wang, C.-H., and N. Chen. 2015. A GIS-based spatial statistical approach to modeling job accessibility by transportation mode: Case study of Columbus, Ohio. Journal of Transport Geography 45: 1-11.

Zhang, L., J. H. Hong, A. Nasri, and Q. Shen. 2012. How built environment affects travel behavior: A comparative analysis of the connections between land use and vehicle miles traveled in US cities. Journal of Transport and Land Use 5(3): 40-52. 